\title{
Retraction Note: Structural strength of loess in mountainous areas and optimization of rural public management services based on 5G Internet of Things
}

\author{
Yue Wang ${ }^{1}$
}

Published online: 3 November 2021

(c) Saudi Society for Geosciences 2021

Retraction Note: Arabian Journal of Geosciences (2021) 14: 1496

https://doi.org/10.1007/s12517-021-07975-7

The Editor-in-Chief and the Publisher have retracted this article because the content of this article is nonsensical. The peer review process was not carried out in accordance with the Publisher's peer review policy. The author has not responded to correspondence regarding this retraction.

The original article can be found online at https://doi.org/10.1007/ s12517-021-07975-7.

Yue Wang

yue2021cg@163.com

1 Department of Humanities and Social Science,

Hebei University of Environmental Engineering,

Qinhuangdao 066000, Hebei, China 